\title{
Developing Product Liability Index for Korean Manufacturing Companies
}

DOI: 10.12776/QIP.V21I2.877

\author{
JunHyeok Seo, SungMin Bae
}

Received: 03 March 2017

Accepted: 29 April 2017

Published: 31 July 2017

\begin{abstract}
Purpose: PL (product liability) response system is an enterprise-wide system that prevents company's financial loss due to PL-related accidents. This study aims at developing an evaluation system for objectively assessing the extent to which companies carry out systematic and organized activities for product liability, including product safety activities, preventive actions, and protective measures.
\end{abstract}

Methodology/Approach: We used the Delphi and analytical hierarchy process methods to develop an evaluation system with product liability experts to present the relative importance of response strategy based on selected evaluation criteria. And then, we carried out systematic and organized PL activities of each industry, scale, and growth stage of the Korean manufacturing companies through PLI.

Findings: In terms of the scale of the manufacturer, Large-sized firms has the highest PLI of 92.32. Also, middle- to large sized firms and middle-sized firms have the highest PLI of 90.63 and 77.35, respectively. And then In terms of the importance of all manufacturers, Awareness was identified as the most important component influencing corporate management activities, with the highest PLI of 78.59 .

Research Limitation/implication: This study is limited due to the small sample size and the number of examples.

Originality/Value of paper: Our paper will enable consumers to determine a manufacturer's response to product liability, and the subsequent positive effects, such as the increase of quality in consumption life.

Category: Research paper

Keywords: product liability (PL); PL response system; Delphi method; analytical hierarchy process; Korean manufacturing companies 


\section{INTRODUCTION}

Accidents caused by defective products invoke negative response from customers in the market and legal sanctions by the government. A failure to address the initial response will affect the corporate image of the company. The company will have to deal with several other problems along with loss of customers and a decrease in sales. In fact, the Diseases Control Department, under the Ministry of Health and Welfare, carried out an epidemiologic study to investigate the deaths of infants and mothers with diseases due to an unknown virus in 2011. It announced that the use of humidifier disinfectants was very likely responsible for the lung disease with unknown cause. The Diseases Control Department told the citizens not to use humidifier disinfectants and recommended manufacturers and sellers to abstain from selling them.

The causes of humidifier disinfectants incident can be divided into two categories. The first category includes the responsibilities of manufacturers that sold the disinfectants with labels stating that they are harmless to human body because the key raw materials for humidifiers, such as polyhexamethylene guanidine (PHMG), Oligo (2-(2-ethoxy)) ethoxyethyl guanidinium chloride $(\mathrm{PGH})$, are chemicals whose hazards have not been verified. The second category includes a failure to carry out the responsibilities for failing to control the hazardous chemicals. These caused the lung disease and resulted in unprecedented casualties of 142 babies and mothers, and a larger magnitude of deaths. This humidifier disinfectant incident resulted in enormous human damage, including reproach toward the government and deterioration of the corporate image, with damaging reports by the mass media, and deterioration of relationship with victims due to the failure of the company to address the initial response in most cases. However, from the beginning of the incident, both the government and manufacturers should have accurately identified the circumstances that led up to the incident, collected the related information, and acted sincerely (Choi, et al., 2012).

In light of the need for more active measures for improving the safety of supplied products, companies should establish a system to facilitate product safety activities for effectively responding to product liability claims, if any, even after various safety standards and specifications are met. For systematizing product safety activities, companies have to make efforts to build a product liability response system to manage the possible response to any product incident in a systematic manner. In addition, the companies must collaborate with an organization to conduct activities to secure product safety during the product life cycle, from the product development stage to the design, manufacturing, shipment, and disposal of the product (Korean Agency for Technology and Standards, 2015).

It would be better if companies can voluntarily undertake the construction of a response system for product liability, which would be successful in protecting consumers from defective products distributed in the market. However, failure to 
protect people from illegal and/or defective products may occur if companies minimize activities to secure product safety and only seek profits, as in the case of people who suffered due to the humidifier disinfectant incident. Accordingly, it is necessary for the government agents to operate a systematic and objective evaluation system, ensure that companies secure product safety continuously, and control their possible response to product accidents. It will help the government in its effort to respond to product accidents in a proper manner, if any, and protect people from defective products distributed in the markets through a product liability response system that is voluntarily implemented by companies.

The study utilized essential components and response strategies of the Product Liability Response System proposed by Seo and Bae (2016) in order to develop a system that can evaluate the operational level of the Product Liability Response System of manufacturing companies.

In order to accomplish the purpose of the study, we conducted a literature survey related to PL and derived operational levels according to the assessment questions and level of responses that were categorized by strategy and evaluation scales (very good, good, moderate, lacking, and very lacking), respectively. In addition, we verified the evaluated items and evaluation ratings by evaluation items through the Delphi method. In addition, AHP method was used to derive the relative importance of response strategies and to calculate the response strategies based on a 100-point scale (Cho, Cho and Kang, 2003; Kim and Choi, 2012; Lee, 2014). Finally, the provision of PLI for each industry, scale, and growth stage of the manufacturing companies through the employment of the evaluation system can help companies understand the operational level of the Product Liability Response System and make up for the product deficiencies. In addition, the consumer can understand the operational level of the Product Liability Response System of the manufacturing company that manufactures the products they purchase. This will help consumers to make further considerations when purchasing the product.

\section{BACKGROUND TO PRODUCT LIABILITY RESPONSE SYSTEM}

A product liability response system should be constructed considering all the departments of a company during the product life cycle, from the stage of purchasing raw materials, processed items, and parts and materials to production, distribution, after-service, and consumption stages, to respond to any product liability in a systematic manner (Song, 2002; Park, Sung and Kang, 2003, Hong, 2003; Lee and Choi, 2005; Hong, 2010; Kim, Lim and Chung, 2011; Seo, Ko and Bae, 2014; Seo and Bae, 2016). The operation of a product liability response system is the least that a company can do to protect people from illegal and/or defective products. It is an important starting point for companies to recognize their social responsibilities to supply safe products to consumers. 
To promote such PLP, PLD, PS strategies in an integrated manner, essential components that either directly or indirectly influence corporate management activities are necessary (Seo, Ko and Bae, 2014; Seo and Bae, 2016). The essential components can be divided into six categories (strategy, organization, training, technology, investment, and awareness) based on literature review and analysis of preceding papers, reports, and research. The roles of these components are as follows. The strategy represents specific response strategy for promoting PL response plans effectively. Organization refers to a corporate response organization that must be established for responding to PL problems effectively. The training represents education and training programs for sufficient understanding among employees to implement the PL measures companywide. The technology represents the technology needed for improving the safety of all products produced by the company in the planning, design, and manufacturing stages, and in identifying the presence of predictable risks. The Investment represents technology securing costs to increase product safety and PL insurance fees to prepare for PL accidents. Lastly, Awareness represents the degree to which participants are aware of PL during all work processes (Song, 2002; Seo, Ko and Bae, 2014; Park, 2014; Seo and Bae, 2016).

Accordingly, manufacturers that have implemented these essential components should operate them systematically for providing a response to possible product accident, if any, although the manufacturers secure product safety from the product designing stage.

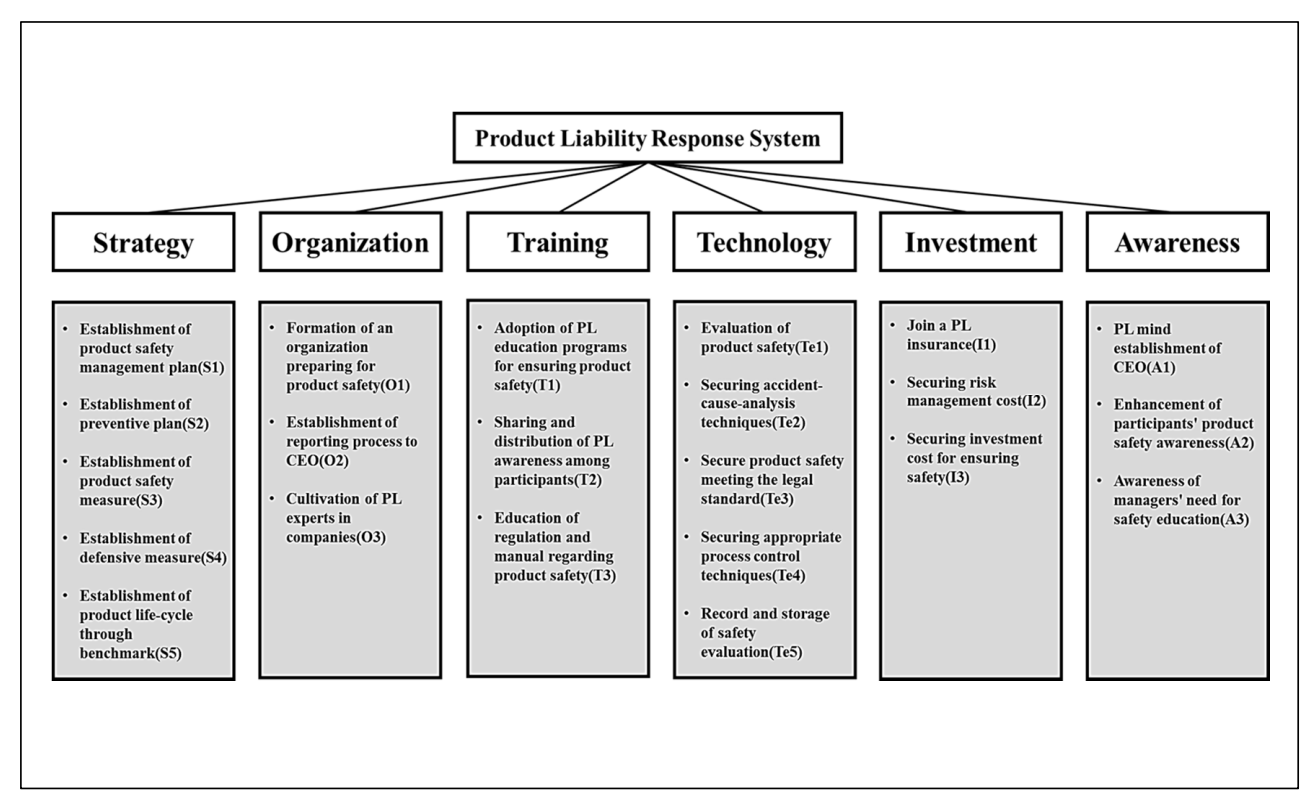

Figure 1 - Product Liability Response System 


\section{METHODOLOGY FOR DEVELOPING THE PRODUCT LIABILITY INDEX (PLI)}

This study aims at developing an evaluation system for objectively assessing the extent to which companies carry out systematic and organized activities for product liability including product safety activities, preventive actions, protective measures, etc. To achieve the purpose of this study, six essential components and 22 response strategies of product liability response system, derived through the preceding study analysis, were used (Seo and Bae, 2016).

We performed this study based on the framework shown in Fig. 2. First, we conducted a literature analysis related to the Product Liability Response System and derived operational levels according to the assessment questions and level of responses categorized by response strategies and evaluation scales (very good, good, moderate, lacking and very lacking), respectively. Subsequently, we conducted an expert survey with PL experts for verifying evaluation scales using the Delphi method. In addition, an AHP method was used to derive the relative importance and priority of essential components and response strategies of product liability response system and to calculate the response strategies based on a 100-point scale. Finally, the evaluation system was extended to derive the Product Liability Index (PLI) for each industry, scale, and growth stage of the manufacturing company.

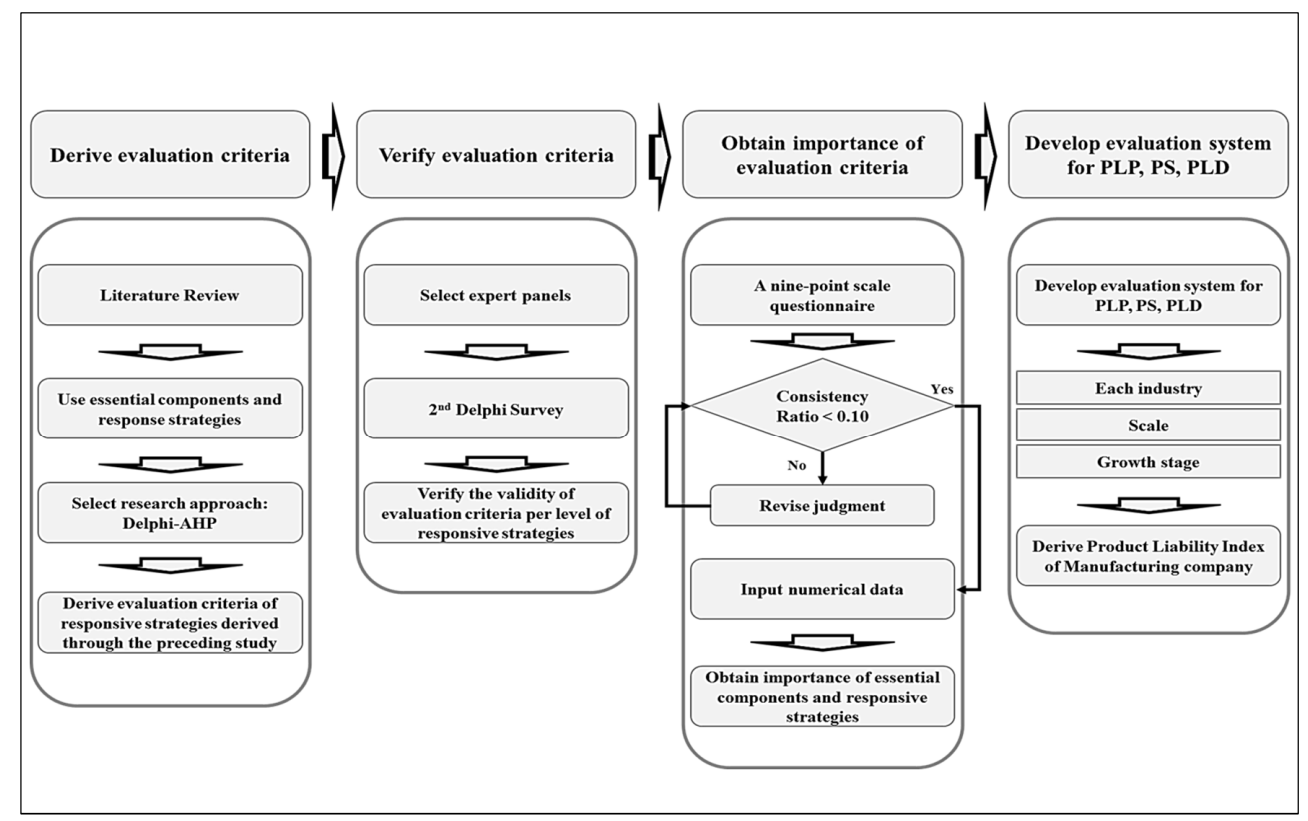

Figure 2 - Development Process of the PLI 


\subsection{Delphi Method}

In this study, we verified the validity of evaluation criteria for 22 response strategies, which were derived through the first questionnaire employed for analysing preceding study. The second questionnaire re-verified the evaluation level of responsive strategies, which were revised from the first questionnaire. The expert panel consisted of 17 voluntary experts, including government officials, researchers, and professors in the field of product liability, chief executive officers, and consultants of manufacturing companies. The participating experts were males aged between 33-57 years, with a mean age of 45.875 years. The work experience of the experts' spanned from 1 year to 27 years, with an average working experience of 14.75 years. Concerning academic qualifications, the panel had four undergraduates, seven master's degree holders, one participant who had completed $\mathrm{Ph}$. D. and five $\mathrm{Ph}$. D. holders. Data collection proceeded with two repetitive surveys from May 1 to June 30 in 2016. The first questionnaire was administered from May 1 to May 31, 2016 and the second questionnaire was administered from June 1 to June 30, 2016.

\subsection{AHP Method}

In this study, we derived the evaluation points on the evaluation criteria of product liability response index through the questionnaire designed by experts. In the survey, after conducting a pairwise comparison of six essential components, using a scale of nine points, the essential comparison of sub-components was conducted. The study conducted a survey from July 1 to July 30 in 2016 using email and fax targeting experts from CEOs of public organizations, consultant, and academia to evaluate the importance of the six essential components of companywide PL response system derived through preceding study analysis. From the collected questionnaires, the combined geometric mean of all values was calculated. These values were evaluated by each component and by every expert in the pairwise comparison matrix that was composed by the experts using the AHP.

\section{VERIFYINICATIG EVALUATION CRITERIA OF THE PLI}

We verified the reliability and validity of the evaluation criteria per responsive strategy derived through the preceding studies. The questionnaire comprised partially open-ended questions that aimed to facilitate the derivation and verification of the response level per responsive strategy of a manufacturer under five evaluation scales, such as very good, good, moderate, lacking, and very lacking. 
Opinions suggested by the panel can be summarized as follows:

- Expert 1: The modification of the evaluation criteria is necessary so that the evaluator can make evaluations objectively.

- Expert 2: Responsive Strategy No. 2, 8, 10, 11, 12, 13, 14, 15, 16, 20, 21, and 22 need modification.

- Expert 3: It is necessary to enter items related to the characteristics of the applicable company in order to make an objective evaluation system in future.

- Expert 4: Responsive Strategy No. 1, 2, 3, 4, 5, 6, 7, 16, and 22 need modification.

Through the second questionnaire, the evaluation criteria in Tab. 1 was developed using 22 responsive strategies for conducting a possible objective evaluation on the response level per responsive strategy for the product liability of a manufacturer.

Table 1 - Evaluation Criteria in the PLI

\begin{tabular}{|l|}
\hline \multicolumn{1}{|c|}{ Evaluation criteria } \\
\hline 1. \\
S1. As for the business policies on product safety suggested below, how many policies \\
has your company established?
\end{tabular}




\section{Evaluation criteria}

13. Te2. Does your company ensure technologies and manpower system to analyze the causes of faults generated in the products manufactured by your company?

14. Te3. Has your company set the procedure that satisfies legal standards on the safety of products manufactured by your company?

15. Te4. Has your company established a system that ensures process management technology to satisfy the requirements of product design?

16. Te5. Has your company established a system for recording and storing details (i.e. manufacturing process, quality management, quality inspection, and repair records) on reviewing product safety?

17. I1. Has your company registered for the PL insurance to prepare for the accidents related to PL?

18. I2. Does your company ensure risk management cost to prepare for the accidents related to PL?

19. I3. Does your company ensure financial investment cost to fulfill product safety and prepare for PL?

20. A1. Is the CEO of your company aware of the importance of PL law?

21. A2. Are the entire managers of your company fully aware of the need for safety training?

22. A3. Are the entire members of your company fully aware of the details on PL as well as product safety?

\section{DETERMINING PRIORITIES OF PLI EVALUATION CRITERIA}

To derive the evaluation grade on the evaluation criteria of the PLI, the evaluated points on essential components and responsive strategies were derived on the basis of 100 points (full score), in consideration of the relative importance and weight of essential components and responsive strategies derived through the AHP method. For this purpose, it was important for the evaluator to provide consistent responses and to ensure the usage of a consistency ratio. Consistency measures the logical inconsistencies of the evaluator's judgment; the degree of consistency is said to be consistent if the consistency ratio does not exceed 0.1.

Tab. 2 shows the relative importance results for essential components of the PLI. In terms of the importance of each essential component of the PLI, Technology is identified as the most important component with a weight of 0.247 , which was followed by Awareness at 0.213 , Strategy at 0.158 , Investment at 0.169 , Training at 0.113 , and Organization at 0.100 , in descending order. Subsequently, the total points per essential components are shown in Tab. 2, where Strategy, Organization, Training, Technology, Investment, and Awareness have 15.8, 10.0, $11.3,24.7,16.9$, and 21.3 points, respectively. 
Table 2 - Essential Components and Response Strategies in the PLI

\begin{tabular}{|l|c|c|c|}
\hline \multicolumn{1}{|c|}{ Components } & Relative weights using AHP & Modification & Percentiles \\
\hline Strategy & 0.158 & $0.158 \times 100$ & 15.8 \\
\hline Organization & 0.100 & $0.100 \times 100$ & 10.0 \\
\hline Training & 0.113 & $0.113 \times 100$ & 11.3 \\
\hline Technology & 0.247 & $0.247 \times 100$ & 24.7 \\
\hline Investment & 0.169 & $0.169 \times 100$ & 16.9 \\
\hline Awareness & 0.213 & $0.213 \times 100$ & 21.3 \\
\hline
\end{tabular}

In the next stage, the evaluation grade of responsive strategies were derived in consideration of total points in the area of essential components, which appeared in Tab. 3, to derive the evaluation points of responsive strategies per essential components. Tab. 3 shows the evaluation points of 22 responsive strategies were derived based on 100.00 points in total (Lee, 2014).

Table 3 - Evaluation Grade of Response Strategy in the PLI

\begin{tabular}{|l|c|c|c|}
\hline \multicolumn{1}{|c|}{ Response Strategy } & $\begin{array}{c}\text { Local } \\
\text { Weights }\end{array}$ & Modification & Percentiles \\
\hline Establishment of product safety management plan (S1) & 0.245 & $0.245 \times 15.8$ & 3.87 \\
\hline Establishment of preventive plan (S2) & 0.203 & $0.203 \times 15.8$ & 3.21 \\
\hline Establishment of product safety measure (S3) & 0.277 & $0.277 \times 15.8$ & 4.38 \\
\hline Establishment of defensive measure (S4) & 0.129 & $0.129 \times 15.8$ & 2.04 \\
\hline $\begin{array}{l}\text { Establishment of product life cycle through benchmark } \\
\text { (S5) }\end{array}$ & 0.146 & $0.146 \times 15.8$ & 2.31 \\
\hline Total & $\mathbf{1 . 0 0}$ & & $\mathbf{1 5 . 8 0}$ \\
\hline Organizational maintenance on product safety (O1) & 0.380 & $0.380 \times 10.0$ & 3.80 \\
\hline Establishment of reporting process to CEO (O2) & 0.238 & $0.238 \times 10.0$ & 2.38 \\
\hline Cultivation of PL experts in companies (O3) & 0.382 & $0.382 \times 10.0$ & 3.82 \\
\hline Total & $\mathbf{1 . 0 0 0}$ & & $\mathbf{1 0 . 0 0}$ \\
\hline $\begin{array}{l}\text { Adoption of PL education programs for ensuring } \\
\text { product safety (T1) }\end{array}$ & 0.299 & $0.299 \times 11.3$ & 3.38 \\
\hline $\begin{array}{l}\text { Sharing and distribution of PL awareness among } \\
\text { participants (T2) }\end{array}$ & 0.236 & $0.236 \times 11.3$ & 2.67 \\
\hline $\begin{array}{l}\text { Education on product safety regulation and manual } \\
\text { (T3) }\end{array}$ & 0.466 & $0.466 \times 11.3$ & 5.27 \\
\hline Total & $\mathbf{1 . 0 0}$ & & $\mathbf{1 1 . 3 1}$ \\
\hline Evaluation of product safety (Te1) & 0.177 & $0.177 \times 24.7$ & 4.37 \\
\hline Securing accident-cause-analysis techniques (Te2) & 0.131 & $0.131 \times 24.7$ & 3.24 \\
\hline $\begin{array}{l}\text { Secure product safety by meeting the legal standards } \\
\text { (Te3) }\end{array}$ & 0.282 & $0.282 \times 24.7$ & 6.97 \\
\hline Securing appropriate process control techniques (Te4) & 0.290 & $0.290 \times 24.7$ & 7.16 \\
\hline
\end{tabular}




\begin{tabular}{|l|c|c|c|}
\hline \multicolumn{1}{|c|}{ Response Strategy } & $\begin{array}{c}\text { Local } \\
\text { Weights }\end{array}$ & Modification & Percentiles \\
\hline Record and storage of safety evaluation (Te5) & 0.120 & $0.120 \times 24.7$ & 2.96 \\
\hline Total & $\mathbf{1 . 0 0}$ & & $\mathbf{2 4 . 7 0}$ \\
\hline Join a PL insurance (I1) & 0.419 & $0.419 \times 16.9$ & 7.08 \\
\hline Securing risk management cost (I2) & 0.253 & $0.253 \times 16.9$ & 4.28 \\
\hline Securing investment cost for ensuring safety (I3) & 0.328 & $0.328 \times 16.9$ & 5.54 \\
\hline Total & $\mathbf{1 . 0 0}$ & & $\mathbf{1 6 . 9 0}$ \\
\hline PL mind establishment of CEO (A1) & 0.542 & $0.542 \times 21.3$ & 11.54 \\
\hline $\begin{array}{l}\text { Enhancement of participants' product safety awareness } \\
\text { (A2) }\end{array}$ & 0.256 & $0.256 \times 21.3$ & 5.45 \\
\hline Awareness of managers' need for safety education (A3) & 0.202 & $0.202 \times 21.3$ & 4.30 \\
\hline Total & $\mathbf{1 . 0 0}$ & & $\mathbf{2 1 . 3 0}$ \\
\hline
\end{tabular}

Tab. 4 shows the derived results of evaluation grade per scale as well as evaluation criteria of the PLI using the evaluation points of essential components and responsive strategies. Considering the derived method, the weight for the points of 22 responsive strategies was given to the level of $80 \%$ (Good), $60 \%$ (Moderate), 40\% (Lacking), and 20\% (Very Lacking) after the full score of 100 points were allocated to the level of excellence (Very Good).

Table 4 - Evaluation Grade of Evaluation Criteria in the PLI

\begin{tabular}{|c|c|c|c|c|c|}
\hline \multirow{2}{*}{ Evaluation criteria } & \multicolumn{5}{|c|}{ Evaluation Grade } \\
\cline { 2 - 6 } & Very Good & Good & Moderate & Lacking & $\begin{array}{c}\text { Very } \\
\text { Lacking }\end{array}$ \\
\hline S1 & 3.87 & 3.10 & 2.32 & 1.55 & 0.77 \\
\hline S2 & 3.21 & 2.57 & 1.93 & 1.28 & 0.64 \\
\hline S3 & 4.38 & 3.50 & 2.63 & 1.75 & 0.88 \\
\hline S4 & 2.04 & 1.63 & 1.22 & 0.82 & 0.41 \\
\hline S5 & 2.31 & 1.85 & 1.39 & 0.92 & 0.46 \\
\hline O1 & 3.8 & 3.04 & 2.28 & 1.52 & 0.76 \\
\hline O2 & 2.38 & 1.90 & 1.43 & 0.95 & 0.48 \\
\hline O3 & 3.82 & 3.06 & 2.29 & 1.53 & 0.76 \\
\hline T1 & 3.38 & 2.70 & 2.03 & 1.35 & 0.68 \\
\hline T2 & 2.67 & 2.14 & 1.60 & 1.07 & 0.53 \\
\hline T3 & 5.27 & 4.22 & 3.16 & 2.11 & 1.05 \\
\hline Te1 & 4.37 & 3.50 & 2.62 & 1.75 & 0.87 \\
\hline Te2 & 3.24 & 2.59 & 1.94 & 1.30 & 0.65 \\
\hline Te3 & 6.97 & 5.58 & 4.18 & 2.79 & 1.39 \\
\hline Te4 & 7.16 & 5.73 & 4.30 & 2.86 & 1.43 \\
\hline
\end{tabular}




\begin{tabular}{|c|c|c|c|c|c|}
\hline \multirow{2}{*}{ Evaluation criteria } & \multicolumn{5}{|c|}{ Evaluation Grade } \\
\cline { 2 - 6 } & Very Good & Good & Moderate & Lacking & $\begin{array}{c}\text { Very } \\
\text { Lacking }\end{array}$ \\
\hline $\mathrm{Te} 5$ & 2.96 & 2.37 & 1.78 & 1.18 & 0.59 \\
\hline $\mathrm{I} 1$ & 7.08 & 5.66 & 4.25 & 2.83 & 1.42 \\
\hline $\mathrm{I} 2$ & 4.28 & 3.42 & 2.57 & 1.71 & 0.86 \\
\hline $\mathrm{I} 3$ & 5.54 & 4.43 & 3.32 & 2.22 & 1.11 \\
\hline $\mathrm{A} 1$ & 11.54 & 9.23 & 6.92 & 4.62 & 2.31 \\
\hline $\mathrm{A} 2$ & 5.45 & 4.36 & 3.27 & 2.18 & 1.09 \\
\hline A3 & 4.3 & 3.44 & 2.58 & 1.72 & 0.86 \\
\hline Total & $\mathbf{1 0 0 . 0 0}$ & $\mathbf{8 0 . 0 0}$ & $\mathbf{6 0 . 0 0}$ & $\mathbf{4 0 . 0 0}$ & $\mathbf{2 0 . 0 0}$ \\
\hline
\end{tabular}

\section{ANALYSIS OF KOREAN MANUFACTURING COMPANY'S PLI}

This study used a system that evaluates the level of response to PL to classify and analyse 40 manufacturers according to the industry, size, and growth stage. The industries to which the manufacturers belonged are classified into rubber and plastic product manufacturing; metal processing, product manufacturing; other machine and equipment manufacturing; other product manufacturing; food manufacturing; medical substance and supply manufacturing; high-precision medical, optical instrument and clock manufacturing; vehicle and trailer manufacturing; electrical device manufacturing; electronic part, computer, video, sound, and telecommunication device manufacturing; and chemical substance and product manufacturing. In terms of the size, the firms are classified into large firms, middle- to large-size firms, middle-size firms, and small-size firms. The growth stages of firms are classified into the stages of decline growth, rapid growth, survival growth, start-up growth, and development growth. The data were obtained based on the representatives of manufacturing firms or quality managers through direct visit, interviews, or telephonic conversation from October 24 to November 11, 2016. Each question in the questionnaire was coded and analysed in the Microsoft Excel.

Tab. 5 shows the result of examining the PLI based on all the manufacturers that participated in the survey. The PLI of manufacturers that participated in the survey is analysed to be 75.41. Specifically, the PLI is $11.31,7.71,7.93,19.31$, 12.42, and 16.74 for strategy, organization, training, technology, investment, and awareness, respectively. Concerning the percentage of PLI based on each factor, training and technology have the lowest PLI at $70.18 \%$ and $78.18 \%$, respectively, and awareness has the highest PLI at $78.59 \%$.

This result indicates that the manufacturers have established strategies that encourage all the corporate members to recognize and understand corporate 
policies fully in order to form response strategies that are different from those of other firms based on the technical skills that ensure product safety and quality.

Table 5 - PLI by Korean Manufacturing Company’s

\begin{tabular}{|c|c|c|c|c|c|c|c|}
\hline Components & Str & Org & Tra & Tech & Invest & Awa & Total \\
\hline Value & 11.31 & 7.71 & 7.93 & 19.31 & 12.42 & 16.74 & 75.41 \\
\hline Full Marks & 15.8 & 10.0 & 11.3 & 24.7 & 16.9 & 21.3 & 100.00 \\
\hline Value/Full Marks & $71.58 \%$ & $77.10 \%$ & $70.18 \%$ & $78.18 \%$ & $73.49 \%$ & $78.59 \%$ & $75.41 \%$ \\
\hline
\end{tabular}

\subsection{PLI Analysis Results by Industry Sector}

The result of examining the PLI based on the industries shows that the index is the highest at 96.45 out of 100 in other machine and equipment manufacturing industries, followed by $90.23,82.68,79.99,77.58,76.32,73.42,67.86,66.73$, 65.45 , and 59.89 in industries manufacturing food products, rubber and plastic products, chemical substance and products, vehicles and trailers, electronic components, high-precision medical and optical instruments, other products, electrical equipment, metal processing products, and medical substances and supply, respectively.

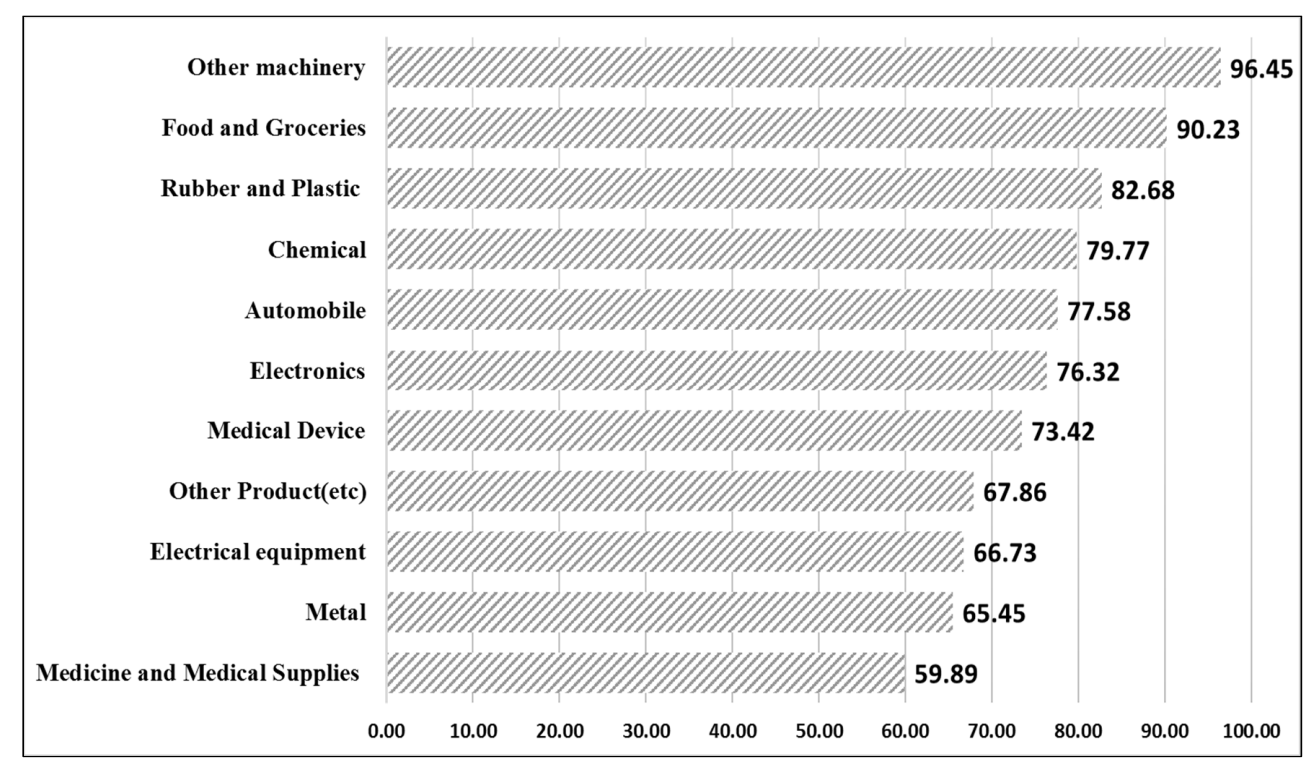

Figure 3 - PLI by the Industry Sector

This result indicates that manufacturers in the industries related to food, chemicals, electronic appliances, and vehicles carry out product safety measures. It can minimize the product-related accidents in all the stages of product planning, design, and production more systematically in these industries than 
those in other industries in that the provision for compensating for damages to persons injured by unsafe products would be extended by the former industries than by the latter more in the former industries than in the latter industries.

\subsection{PLI Analysis Result by Corporate Scale}

The result of examining the PLI according to the corporate scale shows that the index is the highest at 92.32 out of 100 for large-sized firms, followed by 90.63 , 77.35, and 63.03 for middle- to large-sized firms, middle-sized firms, and 63.03 small-sized firms, respectively.

This result verifies that large-sized firms can carry out safety management more systematically than small- to middle-sized firms based on their abundant funding, technology, work force, systems, and other fields related to product liability. As the small- to middle-sized firms are exposed to inadequate environments compared to large-sized firms, they should establish response strategies for conducting PL based on strategic prioritization of limited resources throughout the enterprise and encourage the active participation of CEOs. In addition, they should perform education and training for employees to increase their awareness on the importance of PL and execute response strategies for fostering in-house PL experts.

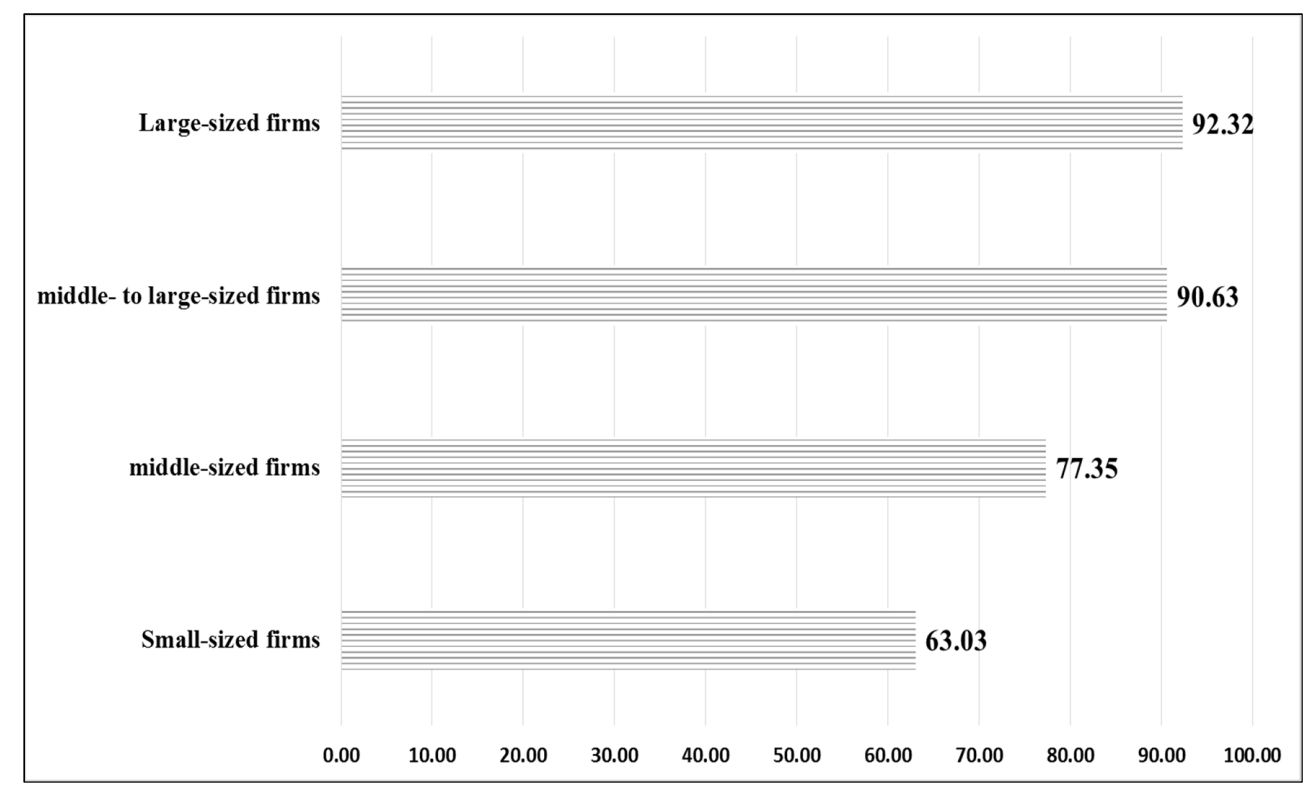

Figure 4-PLI by Corporate Scale 


\subsection{PLI Analysis Results by Stages of Corporate Growth}

The result of examining the PLI according to the stages of corporate growth shows that the index is the highest of 77.67 out of 100 for the firms in the rapid growth stage, followed by 77.24 for those in the stage of survival, 73.95 for those in the stage of development, 70.41 for those in the stage of start-up, and 52.54 for those in the stage of decline. This result is derived because firms in the stage of high growth take the lead in industrial and technical standards when they release new products and establish PL response strategies by reviewing the potential safety problems of products to ensure competitiveness in the market.

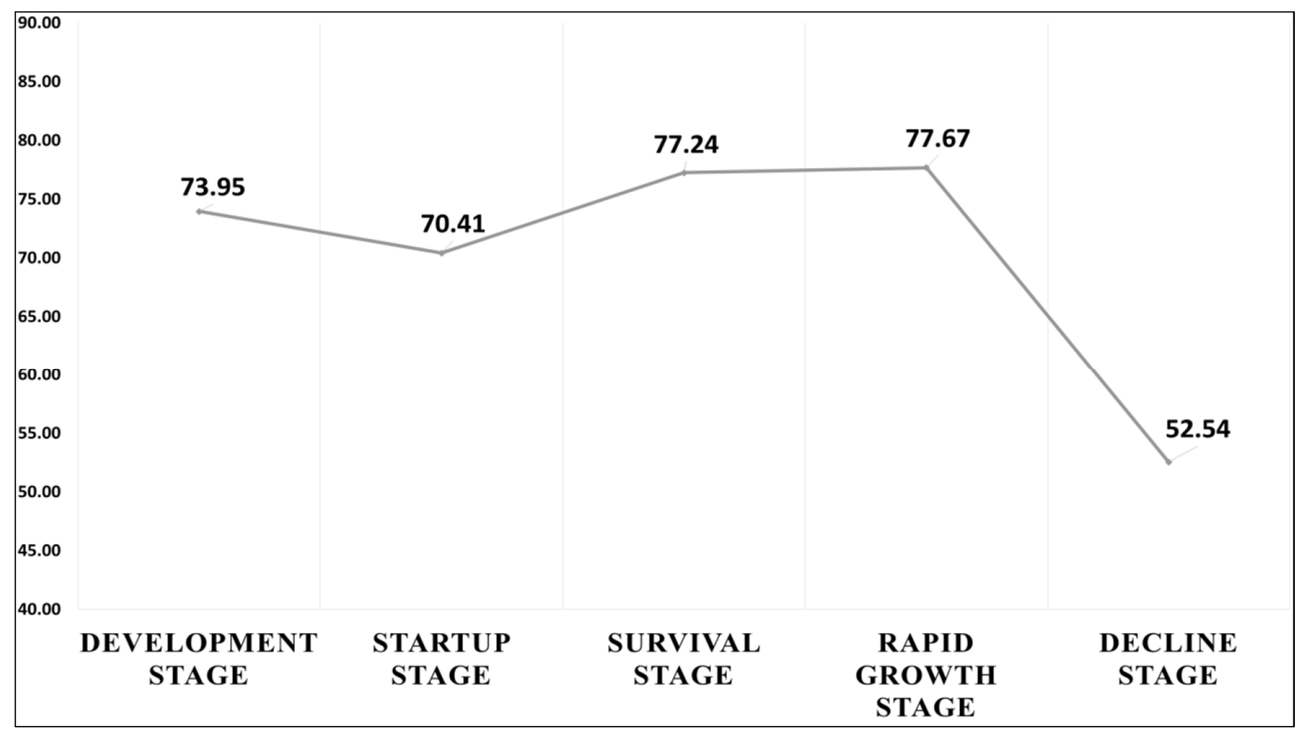

Figure 5 - PLI by Corporate Growth Stage

\section{CONCLUSIONS}

It is beneficial for companies to protect consumers from defective products distributed in the markets through voluntary management activities. Moreover, incidents may reoccur with a greater impact on the safety and life of people, if the companies solely seek profits over activities that secure product safety, as shown in the humidifier disinfectant incident. Therefore, it is necessary to introduce a certification system for conducting objective evaluation to ensure that the safety of products manufactured by companies can be voluntarily secured with a reasonable response to product accidents, if any.

This study has developed the evaluation standards and scoring system based on evaluation standards, which can objectively assess the PL activities of manufacturers, by analysing previous studies on PL and using the Delphi and AHP methods that can collect the individual opinions and insight of many experts. Moreover, it has identified the level of manufacturers according to the 
industries, size, and growth stages by practically applying the PL response level evaluation system in order to provide base data that can be used to constantly increase the quality of products manufactured by these firms.

Study results can be briefly summarized as follows. The PLI of manufacturers that participated in the survey is found to be 75 out of 100 , thus indicating that these firms mainly carry out strategies for applying technology that can ensure safety and quality from the stage of product design and helping corporate members to fully recognize the importance of PL. In terms of the industries, manufacturers in the industries where PL accidents occur frequently and liability for damages is great conduct PL activities more systematically. As for the scale of firms, large-size firms that ensure more abundant funding, technology, and manpower perform more systematic activities than small- to middle-size firms that are exposed to inadequate environments. Finally, Rapid growth firms that take the lead in the market execute response strategies that ensure product competitiveness and quality more constantly than firms in the stages of start-up and decline.

Through the findings of this study, manufacturers may effectively secure product safety in constant collaboration with an organization that has a system for providing reasonable responses to possible product accidents. In addition, the study provides information with which consumers can identify the product liability response level of a manufacturer. In addition, the study highlights the positive effects of product liability response, such as maintaining quality throughout the product life cycle

However, this study is limited by its sample size and only a few companies were surveyed due to limited budget and time. Thus, it is hoped that further research will be conducted with more data, thereby supplementing the limitations of this study.

\section{ACKNOWLEDGMENTS}

This research was supported by the research fund of Hanbat National University in 2016.

\section{REFERENCES}

Cho, G.T., Cho, Y.G. and Kang, H.S., 2003. Analytic Hierarchy Process. Seoul: DongHyeon Press.

Choi, Y.Y., Lim, H.K., Lim, S.Y. and Paek, D.Y., 2012. Health Damages and Lessons of the Humidifier Disinfectants in Korea. Korean Society of Environmental Health, 38(2), pp.166-174. 
Hong, H.K., 2003. A Study on the case of PL prevention strategies and prevention systems in the domestic S-company. Journal of the Korean Society for Quality Management, 31(1), pp.62-75.

Hong, H.K., 2010. Analysis on the type of PL Accident by Major Industry. Journal of economy and business, 5(1), pp.125-134.

Kim, K.D. and Choi, K., 2012. A Study on the Policy of Sustainable Domestic Timber Supply Using Delphi Technique and AHP. Journal of Korean Forest Society, 101(3), pp.434-442.

Kim, K.S., Lim, G.C. and Chung, S.S., 2011. A Study on the PL Response by Integrated Management System. Journal of Korean Society for Quality Management, 39(1), pp.120-130.

Korean Agency for Technology and Standards, 2015. Safety Korea. [online] Available at: <https://www.iso.org/member/1663.html> [Accessed 15 June 2017].

Lee, S.M. and Choi, S.C., 2005. A Study on the Strategies for Product Liability in the Food Service Industry. Journal of Digital Contents Society, 5(5), pp.219227.

Lee, S.S., 2014. The Study on Bottled Water of Quality Index (WQI) Development. Ph. D. Graduate School of KyungHee University.

Park, J.S., Sung, H.K. and Kang, G.S., 2003. A Study Countermeasures Method of Domestic Small and Medium Enterprise According to Product Liability Law. Journal of Korea Safety Management \& Science, 4(1), pp.81-92.

Park, Y.T., 2014. Quality Management. Seoul: Korean Standards Association Media.

Seo, J.H. and Bae, S.M., 2016. Identifying Industry-Specific Components of PL Response system using Delphi-AHP Method. Management and Production Engineering Review, 7(4), pp.27-38.

Seo, J.H., Ko, B.S. and Bae, S.M., 2014. Extracting Priorities of Strategic Components of Product Liability Response System using AHP. Journal of Korean Society for Quality Management, 42(2), pp.235-252.

Song, J.H., 2002. Product Liability Act and Corporate Strategies. Seoul: Seongandang.

\section{ABOUT AUTHORS}

JunHyeok Seo is a PhD. student at the Dept. of Industrial and Management Engineering at Hanbat National University in Korea. His research interests mainly include Product Liability and AHP Technique, e-mail: co903@hanbat.ac.kr. 
SungMin Bae is a professor at the Dept. of Industrial and Management Engineering at Hanbat National University in Korea. His research areas include (but not limited to) Data Mining, Manufacturing Information System, Patent Information Analysis, and the Internet of Things, e-mail: loveiris@hanbat.ac.kr.

(C) 2017 by the authors. Submitted for possible open access publication under the terms and conditions of the Creative Commons Attribution (CC-BY) license (http://creativecommons.org/licenses/by/4.0/). 